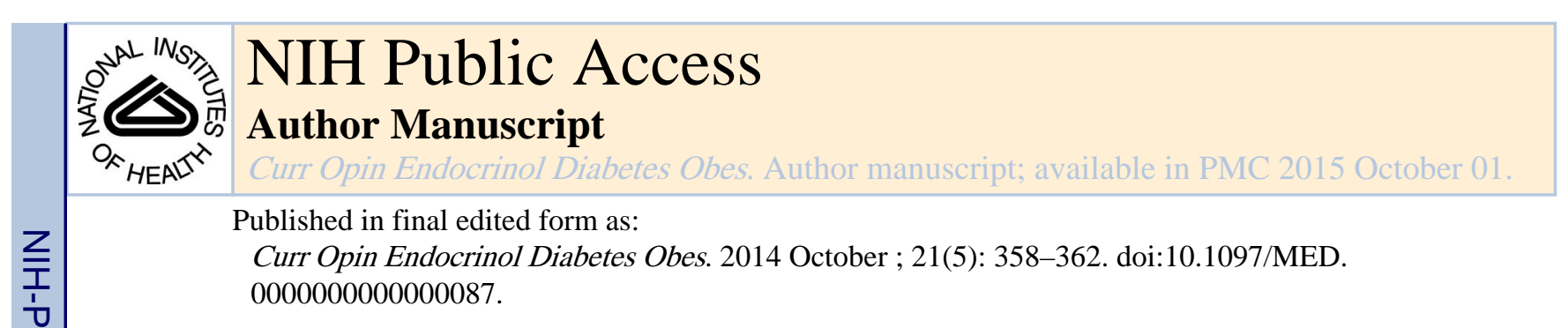

\title{
Weight Loss and Bone Mineral Density
}

Gary R. Hunter, Eric P. Plaisance, and Gordon Fisher

All Division of Kinesiology, University of Alabama at Birmingham

\section{Abstract}

Purpose of the Review-Despite evidence that energy deficit produces multiple physiological and metabolic benefits, clinicians are often reluctant to prescribe weight loss in older individuals or those with low BMD, fearing BMD will be decreased. Confusion exists concerning the effects weight loss has on bone health.

Recent Findings-Bone density is more closely associated with lean mass than total body mass and fat mass. Although rapid/large weight loss is often associated with loss of bone density, slower/smaller weight loss is much less apt to adversely affect BMD, especially when it is accompanied with high intensity resistance and/or impact loading training. Maintenance of calcium and vitamin D intake seems to positively affect BMD during weight loss. While dual energy X-ray absorptiometry is normally used to evaluate bone density, it may overestimate BMD loss following massive weight loss. Volumetric quantitative computed tomography may be more accurate for tracking bone density changes following large weight loss.

Summary-Moderate weight loss does not necessarily compromise bone health, especially when exercise training is involved. Training strategies that include heavy resistance training and high impact loading that occur with jump training may be especially productive in maintaining, or even increasing bone density with weight loss.

\section{Keywords}

exercise training; high impact loading; calcium; vitamin D

\section{Introduction}

It is generally assumed that overweight/obese individuals are protected against low bone mineral density (BMD) and fractures to a greater extent than normal weight individuals [1, 2]. Consistent with this assumption, several [3,4] but not all [5] studies have shown a decrease in BMD with weight loss. It is postulated that the decrease in BMD during weight loss may be due to decreased mechanical loading of bones during locomotion, and increased calcium loss resulting from a combination of reduced parathyroid hormone and extraovarian estrogen production [3, 4]. Despite extensive evidence that energy deficit produced by exercise and/or energy restriction produces multiple physiological and metabolic benefits,

Corresponding Author: Gary R. Hunter, PhD, Division of Kinesiology/Human Studies Department, University of Alabama at Birmingham, Birmingham, Al 32294, 9348338 ghunter@uab.edu.

The authors have no conflicts of interest. 
clinicians are often reluctant to prescribe weight loss in older individuals or those with low BMD. One of the primary physiological benefits of exercise during weight loss is maintenance of skeletal muscle mass. Maintaining and potentially increasing skeletal muscle mass are important as BMD has been shown to be more closely associated with lean body mass than fat mass. This is consistent with the observation that relative bone density may increase following weight loss if skeletal muscle mass is maintained during exercise [6]. The following is a brief review of the pertinent papers concerning BMD and weight loss published during 2013 and the first few months of 2014.

\section{Obesity and BMD}

Confusion still exists over the effects of obesity on BMD. Increased body weight has been generally associated with increased BMD while low body weight or severe reductions in body weight is often associated with decreased BMD. Indeed, overweight/obesity is associated with increased bone size and strength in adolescents [7, 8], and adults [9] while eating disorders which produce rapid reductions in body weight, such as anorexia nervosa and bulimia, are associated with low BMD and poor bone health [10, 11]. In addition, female athletes with lower body weight/BMI tend to have low BMD [12]. The incidence of low BMD is higher in female athletes in the presence of oligo/amenorrhea or delayed menarche [12]. Furthermore, in sedentary populations such as breast cancer survivors [13] or chronic obstructive pulmonary disease (COPD) patients [14], both body weight and lean mass are positively associated with BMD. While body weight is often used when assessing the relationship between weight loss and BMD, multiple studies have reported lean weight to be a much stronger correlate of BMD than body weight or BMI, while no relationship between fat mass and BMD $[8,15-17]$ has been found in several studies.

\section{Effects of Weight Loss Produced by Diet and/or Exercise on BMD}

Bone mineral density decreases with diet-induced weight loss [18-20], and at least in postmenopausal women, does not return to pre-weight loss levels with weight regain [20]. Although it is impossible to understand how age-related losses in BMD contribute to the losses observed across the 2 year follow-up, these findings suggest that weight loss produces long-term impairments in BMD of postmenopausal women. On the other hand, recent studies in older adults show that moderate energy restriction and regular exercise produces weight loss and improves mortality risk without adversely affecting muscle and BMD [21]. When calcium intake is conserved during energy restriction, BMD is conserved despite a $10 \%$ loss of body weight in young adults [22]. Consistent with the hypothesis that dietinduced weight loss does not adversely affect bone health, relative (adjusted for body weight) hip and spine BMD increased following a diet-induced $12 \mathrm{~kg}$ weight loss in both exercising and non-exercising pre-menopausal women. The increase in relative BMD was maintained 1 year following weight loss in women who either regained weight or maintained weight during the follow-up [19]. In addition, section modulus (a measure of resistance to bending) at the hip neck did not change following weight loss or 1 year following weight loss. Taken together, the results of this study suggest that although absolute BMD may be reduced, the BMD relative to the new body weight is actually enhanced and maintained for one year following weight loss, possibly reducing the risk of 
fracture. In another study, obese older adults who participated in an energy restriction/ exercise program did not change BMD differently from control subjects who neither exercised nor lost weight while a group that only exercised increased BMD [6]. Changes in BMD were correlated to changes in thigh muscle volume supporting the hypothesis that weight loss does not affect BMD adversely as long as muscle is maintained with exercise training [6]. Just as reduced loading of bone such as that experienced during weight loss or bed rest in humans and tail suspensions in rodents induce dramatic decreases in BMD [23], high forces that are rapidly developed may increase bone density by increased loading. Jump exercise during hindlimb unloading protects against adverse changes in trabecular bone microarchitecture in young rats [23]. Consistent with the premise that high impact loading may positively affect bone health even in very lean young women ( 16\% fat), gymnasts increased BMD at the lumbar spine and femoral neck more than runners and controls following 8 months of training and more than swimmers following 12 months of training [24]. These changes occurred despite the gymnasts starting the study with relatively high BMD. Presumably, a similar strategy using high impact loading may be successful in preventing loss of BMD during energy restriction dietary interventions.

\section{Muscle and BMD}

As indicated above, muscle is more strongly related to BMD than fat or body weight. Interestingly, myostatin, a member of the transforming growth factor superfamily, inhibits satellite cell augmentation and differentiation, two factors that are necessary for growth of skeletal muscle. In animals, myostatin inhibition leads to increased lean mass and bone formation and decreased fat mass [25]. It is not known whether myostatin has a direct effect on bone or whether its effect on bone is through changes in muscle. Thus, future research should examine the potential relationship between myostatin and bone formation in humans.

Consistent with the concept that maintenance of lean tissue and prevention of fat mass gain may be important for maintaining bone health, loss of lean tissue $(0.9 \%)$ and gain in fat (9

$\%$ ) occurred concomitantly with a decrease in bone mass (1.6\%) across 5 years in 1329 men aged 25 to 96 years [26]. The majority of existing literature has consistently shown that resistance training is the best strategy for maintaining lean tissue during weight loss, while aerobic training seems to have only a minimal effect on preservation of lean tissue during energy restriction-induced weight loss [27]. Interestingly, a combination of resistance and high impact jump training was successful at reducing the loss of BMD at L6 in a group of 70 year old prostate cancer survivors [28]. Importantly these older prostate cancer survivors seemed to tolerate the high impact jump training well. Therefore, it seems prudent to include resistance training during diet- induced weight loss in order to maintain lean tissue and BMD.

\section{Effect of Macronutrient Variation on BMD}

It has been hypothesized that high protein western diets can induce metabolic acidosis and hypercalciuria, which may negatively impact bone health by lowering BMD, resulting in an increased fracture rate $[29,30]$. Consistent with this, high protein intake is accompanied by increased acidity of the blood [31], while ammonium chloride $\left(\mathrm{NH}_{4} \mathrm{CL}\right)$ induced chronic 
metabolic acidosis in rats resulted in decreased muscle cross-sectional area, cortical bone thickness, BMD, and trabecular bone volume [32]. However, contrary to these findings a weight loss study using a high protein $\operatorname{diet}(\sim 25 \%)$ for two years in pre-menopausal women found no adverse effects of high protein diet on BMD despite increases in hypercalciuria [29]. In addition, it is proposed that a high protein diet may actually help to conserve bone density during dietary weight loss by preserving muscle [33]. Therefore, given the discrepancies between findings, additional studies are required to determine if a threshold of protein consumption exists that may alter BMD and functional status of bone, and if differences exist between men and women during the aging spectrum with regards to protein consumption. In addition, studies are needed to determine the impact of variable protein consumption during the exponential growth phase in children when protein intake is more crucial to growth expansion.

Vitamin D is often linked to BMD and overall bone health as evidenced by the frequency of vitamin D supplementation in foods and recommendations to accumulate sun exposure during the photoperiod. Previous studies show that low vitamin $\mathrm{D}$ is often associated with reduced BMD. However, a recent study showed that high 25-hydroxyvitamin D (mean level $56 \mathrm{nmol} / \mathrm{l}$ ) was not associated with 5 year BMD losses in femoral neck and lumbar spine of older Japanese women [34]. Given that the available evidence does not provide unequivocal evidence on the relationship between high protein intake, 25-hydroxy D levels, and BMD, additional studies should be performed in different populations, age groups and in the presence of weight loss to resolve these discrepancies.

\section{Gastric Bypass Surgery-Mediated Effects on BMD}

Roux-en-Y gastric bypass (RYGB) surgery produces profound and rapid changes in metabolism that precede weight loss in morbidly obese individuals. Within 2-3 weeks of the surgical procedure, patients experience weight loss that produces additional physiological and metabolic benefits. However, the rapid reduction in body weight lowers BMD in a fashion that may be similar to weight loss produced by negative energy balance, i.e. reductions in mechanical loading, calcium, and vitamin D malabsorption [35]. However, a recent Roux-en-Y gastric bypass surgery study on rats indicates that the initial decreases in calcium absorption are more associated with metabolic acidosis rather than reduced 1,25dihydroxyvitamin D decrease [36]. Although, mechanisms for potential BMD loss following Roux-en-Y surgery are unknown at this time, a recent review by $\mathrm{Yu}$ [37] points out that recent studies show that reduction in serum vitamin $\mathrm{D}$ and parathyroid hormone do not accompany these BMD losses.

One of the important caveats to this conclusion raised from recent RYGB studies is that when morbidly obese individuals lose large amounts of body weight, dual energy X-ray absorptiometry (DXA) may overestimate loss of bone density. DXA has been considered to be the gold standard for measuring BMD over the past 15-20 years, but the rapid weight loss produced by RYGB has forced a closer evaluation of DXA in this environment.

Volumetric quantitative computed tomography (QCT) is a technique that may be more accurate for tracking bone density changes following large weight loss, i.e. > $30 \mathrm{~kg}$. A recent 
study that evaluated BMD changes following RYGB surgery ( $\sim 35 \mathrm{~kg}$ weight loss) found that proximal BMD femur loss was less when using QCT as compared to DXA [38]. In addition, spine BMD did not change when using QCT despite significant decreases in spine BMD using DXA. It is impossible to definitively determine which imaging technique is more accurate; however, several studies suggest that DXA may be more susceptible to artifacts than QCT. One problem is that DXA is restricted to two different X-ray beam energies, but is used to assess three different tissues (bone, fat, and lean tissue). Furthermore, DXA algorithm assumes that the fat:lean tissue ratios across a region of interest are similar. In the morbidly obese and during large weight loss this assumption may not be met. This may be particularly problematic when there is a large abdominal pannus that overlays the hip area. It should also be mentioned that intraosseous bone marrow fat can affect both DXA and QCT measurements. Since there is no universally accepted method for evaluation of BMD in the morbidly obese, it is difficult to determine which technique is more accurate in this population. Despite the lower measures of BMD loss in the QCT group reported in the above study, it is probable that BMD was reduced since there was a marked change in bone turnover markers following the gastric bypass surgery [38].

\section{Summary}

Maintaining bone health and a healthy body composition is critical for healthy aging. Given the high prevalence of obesity and comorbidities associated with adiposity, it is important to further our understanding of the relationship between BMD and body composition. It is especially critical that we identify optimal strategies for weight loss that do not compromise bone health. As suggested in Figure 1, recent results suggest that moderate weight loss does not necessarily compromise bone health, especially when exercise training is involved. This may be particularly relevant when exercise training includes significant stress on bones. Training strategies that include heavy resistance training and high impact loading that occur with jump training may be especially productive in maintaining, or even increasing bone density with weight loss. While we have made great strides in recent years in our understanding of changes in BMD during weight loss, partly due to advances in measurement techniques, there are still a number of questions that remain. One of the primary questions concerns the optimal modes, frequencies, volumes, or intensities of exercise for maintaining BMD during weight loss. We also have little understanding of what happens to BMD during massive weight loss such as occurs with gastric bypass surgery. For example, we do not know if weight loss is associated with malabsorption of important nutrients, decreased loading of bone, or other unanticipated factors. Future research should focus on improving our understanding of the interaction of rate of weight loss and exercise mode, frequency, intensity, and volume on BMD changes.

\section{Acknowledgments}

Funding: NIH R01AG027084, RO1DK51684, RO1DK49779, UL 1RR025777, P60DK079626, MO1-RR-00032, P30-DK56336, T32HL105349, and 2T32DK062710-07

\section{Reference List}

Papers of particular interest have been highlighted as: 
*Of special interest

**Of outstanding interest

1. Bainbridge KE, Sowers M, Lin X, Harlow SD. Risk factors for low bone mineral density and the 6year rate of bone loss amoung premenopausal and postmenopausal women. Osteoporos. Int. 2004; 15:439-446. [PubMed: 15205714]

2. Wilsgaard T, Emans N, Ahmed LA, Gimnes G, Joakimsen RM, Omsland TK, Bernsten GR. Lifestyle impact on lifetime bone loss in women and men: the Tromso Study. Am. J. Epidemiol. 2009; 169:877-886. [PubMed: 19174426]

3. Jensen LB, Kollerup G, Quaade F, Sorensen OH. Bone minerals changes in obese women during a moderate weight loss with and without calcium supplementation. Bone Min Res. 2001; 16:141-147.

4. Villareal DT, Fontana L, Weis EP, Racette SB, Steger-May K, Schechtman KB, Klein S, Holloszy JO. Bone mineral density response to caloric restriction-induced weight loss or exercise-induced weight loss: a randomized controlled trial. Arch. Intern. Med. 2006; 166:2502-2510. [PubMed: 17159017]

5. Bosy-Westphal A, Later W, Schautz B, Lagerpusch M, Goele K, Heller M, Gluer C, Muller MJ. Imact of intra-and extra-osseous soft tissue composition on changes in bone mineral density sith weight loss and regain. Obesity. 2011; 19:1503-1510. [PubMed: 21372803]

6. Armamento-Villareal R, Aquirre L, Napoli N, Shah K, Hilton T, Sinacore DE, Qualis C, Villareal DT. Changes in thigh muscle volume predict bone mineral density reponse to lifestyle therapy in frail, obese older adults. Osteoporos Int. 2014; 25:551-558. [PubMed: 23892583] Shows that bone mineral density can be preserved during weight loss as long as muscle is preserved with exercise training.

7. Vandewalle S, Taes Y, Van Helvoirt M, Debode P, Herregods N, Ernst C, Roef GVCE, Roggen I, Verhelle F, Kaufman JM, De Scjepper J. Bone size and bone strength are increased in obese male adolescents. J Clin Endo Met. 2013; 98:3019-3028.

8. Mosca LN, Nobrega da Silva V, Beres alederer Goldberg T. Does excess weight interfere with bone mass accumulation during adolescence? Nutrients. 2013; 5:2047-2061. [PubMed: 23743968]

9. Zhao LJ, Jiang H, Papasian DJ, Maulik D, Drees B, Hamilton J, Deng HW. Correlation of obesity and osteoporosis:effect of fat mass on the determination of osteoporsis. J Bone Min Res. 2008; 23:17-29.

10. Zuckerman-Levin N, Hochberg Z, Latzer Y. Bone health in eating disorders. Obesity Rev. 2013 Epub ahead of print.

11. Howgate DJ, Graham SM, Leonidou A, Korres N, Tsiridis E, Tsapakis E. Bone metabolism in anorexia nervosa: molecular pathways and current treatment modalities. Osteoporos Int. 2013; 24:407-421. [PubMed: 22875459]

12. Gibbs JC, Nattiv A, Barrack MT, Williams NI, Rauh MJ, Nichols JF, De Souza MJ. Low bone density risk is higher in exercising women with multiple triad risk factors. Med Sci Sports Exerc. 2014; 46:167-176. [PubMed: 23783260]

13. George S, Mctiernan A, Villasenor A, Alfano CM, Irwin ML, Neuhouser ML, Baumgartner RN, Baumgartner KB, Bernstein L, Smith AW, Ballard-Barbash R. Disentangling the body weightbone mineral density association among breast cancer survivors: and examination of the independent roles of lean mass and fat mass. BMC Cancer. 2013; 13:1-6. [PubMed: 23282137]

14. Yamamoto Y, Yoshikawa M, Tomoda K, Fujita Y, Yamauchi M, Fukuoka A, Tamaki S, Koyama $\mathrm{N}$, Kimra H. Distribution of bone mineral content is associated with body weight and exercise capacity in patients with chronic obstructive pulmonary disease. Respiration. 2013; 87:158-164. [PubMed: 24334752]

15. Katzmarzyk PT, Barreira TV, Harrington DM, Staiano AE, Heymsfield SB, Bimble JM. Relationship between abdominal fat and bone mineral density in white and African American adults. Bone. 2011; 50:1415-1418.

16. Madeira E, Mafort TT, Madeira M, Guedes EP, Moreira RO, de Mendonca LM, Lima IC, de Pinho RR, Lopes AJ, Farias ML. Lean mass as a predictor of bone density and microarchitecture in adult obese individuals with metabolic syndrome. Bone. 2014; 59:89-92. [PubMed: 24220493] 
17. Lu H, Fu X, Ma X, He W, Wang Z, Allison Db, Heymsfield SB, Zhu S. Relationships of percent body fat and percent trunk fat with bone mineral density among Chinese, black, and white subjects. Osteopor Int. 2011; 22:3029-3035.

18. Waters DL, Ward AL, Villareal DT. Weight loss in obese adults 65 years and older: a review of the controversy. Exp. Gerontol. 2013; 48:1054-1061. [PubMed: 23403042]

19. Hamilton KC, Fisher G, Roy JL, Gower BA, Hunter GR. The effects of weight loss on relative bone mineral density in premenopausal women. Obesity. 2013; 21:441-448. [PubMed: 23404937] Shows that relative bone mineral density may actually increase during weight loss and that this increase in relative bone density is maintained for one year following weight loss.

20. Von Thun NL, Sukumar D, Heymsfield SB, Shapses SA. Does bone loss begin after weight loss ends? Results 2 years after weight loss or regain in postmenopausal women. Menopause. 2013 Eub ahead of print.

21. Darmon P. Intentiaonal weight loss in older adults: useful or wasting disease generating strategy? Curr Opin Clin Nutr Met Care. 2014; 16:284-289. Demonstrates that weight loss can occur without adverse affects on bone density.

22. Redman LM, Rood J, Anton SD, Champagne C, Smith SR, Ravussin E. Calorie restriction and bone health in young, overweight individuals. Arch. Intern. Med. 2008; 168:1859-1866. [PubMed: 18809812]

23. Ju YI, Stone T, Ohnaru K, Choi KA, Fukunaga M. Jump exercise during hindlimb unloading protect against the deterioration of trabecular bone microarchitecture in growing young rats. Springer Plus. 2013; 2:35-42. [PubMed: 23503945]

24. Taaffe DR, Robinson TL, Snow CM, Marcas R. High-impact exercise promotes bone gain in welltrained female athletes. J. Bone Miner. Res. 1997; 12:255-260. [PubMed: 9041058]

25. Buehring B, Binkley N. Myostatin - the holy grail for muscle, bone, and fat? Curr Ostopor Report. 2013; 11:407-414.

26. Pasco JA, Gould H, Brennan SL, Nicholson GC, Kotowicz MA. Musuloskeletal deterioration in men accompanies increases in body fat. Obesity. 2013:1-5. Epub ahead of print.

27. Hunter GR, Byrne NM, Sirikul B, Fernandez JR, Zuckerman PA, Darnell BE, Gower BA. Resistance training conserves fat free mass and resting energy expenditure following weight loss. Obesity. 2008; 16:1045-1051. [PubMed: 18356845]

28. Winters-Stone KM, Dobek JC, Bennett JA, Maddalozzo GF, Ryan CW, Beer TM. Skeletal response to resistance and impact training in prostate cancer survivors. Med Sci Sports Exerc. 2014 Epub ahead of print.

29. Jesudason D, Nordin BEC, Keogh J, Clifton P. Comparison of 2 weight-loss diets of different protein content on bone health: a randomized trial. Am. J. Clin. Nutr. 2013; 98:1343-1352. [PubMed: 24047916]

30. Clifton P. Effects of high protein diet on body weight and comorbidities associated with obesity. Br. J. Nutr. 2014; 108:S122-S129. [PubMed: 23107523]

31. Hunter GR, Van Huss WD, Pheil NA. The effects of sodium bicarbonate ingestion and alteration in diet on acid-base balance of the blood. J Res Sport Phys Ed Rec. 1984; 7:5-15.

32. Gasser JA, Hulter HN, Imboden P, Krapf R. Effect of chronic metabolic adidosis on bone density and bone architecture in vivo in rats. Am J Physiol: Ren Physiol. 2013 Epub ahead of print.

33. Tang M, O'Connor LE, Campbell WW. Diet induced weight loss:the effect of dietary protein on bone. J Acad Nutr Diatet. 2014; 114:72-85.

34. Kitamura K, Nakamura K, Saito T, Kobayashi R, Oshiki R, Nishiwaki T, Iwasaki M, Yoshihara A. High serum 25-hydroxyvitamin D levels do not retard postmenopausal bone loss in Japanese women: Yokogoshi study. Arch Osteopor. 2013; 8:153-157.

35. Hage MP, El-Haij Fuleihan G. Bone and mineral metabolism in patients undergoing Roux-en-Y gastric bypass. Osteopor Int. 2013 EPub ahead of print.

36. Abegg K, Gehring N, Wagner CA, Liesegang A, Schiesser M, Bueter M, Lutz TA. Roux-en-Y gastric bypass surgry reduces bone mineral density and induces metabolic acidosis in rats. Am. J. Physiol. 2014; 305:R999-R1009.

37. Yu EW. Bone metabolism after bariatric surgery. J. Bone Miner. Res. 2014 Epub ahead of print. 
38. Yu EW, Bouxsein M, Roy AE, Baldwin C, Cange A, Neer RM, Kaplan LM, Finkelstein JS. Bone loss after bariatric surgery: Discordant results between DXA and QCT bone density. J Bone Min Res. 2013 Epub ahead of print. 


\section{Key Points}

- Moderate rate of weight is not associated with loss of BMD.

- Resistance training and/or high impact training such as jump training associate with maintenance/increase in BMD during weight loss.

- Maintenance of calcium and vitamin D intake during weight loss is associated with maintenance of BMD. 


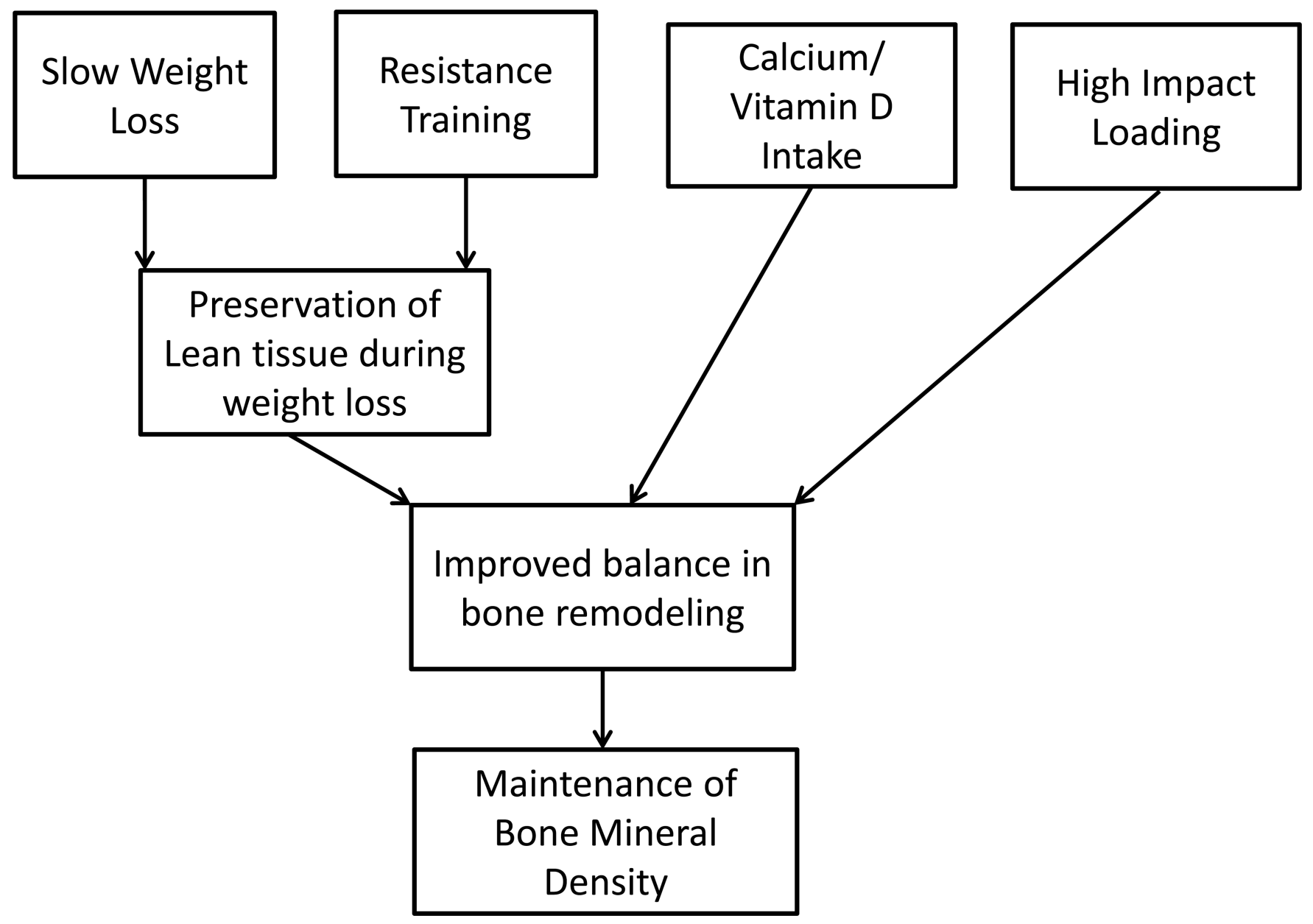

Figure 1.

Model for Maintaining Bone Mineral Density during Weight Loss 